OPEN ACCESS

Edited by:

Mariana Teles,

University of Porto, Portugal

Reviewed by:

Gabriela Verónica Aguirre-Martínez,

Universidad Arturo Prat, Chile

Lluis Tort,

Autonomous University of Barcelona, Spain

*Correspondence:

Bettie Cormier

bettie.cormier@u-bordeaux.fr

Steffen H. Keiter

steffen.keiter@oru.se

Specialty section:

This article was submitted to

Marine Pollution,

a section of the journal

Frontiers in Environmental Science

Received: 15 February 2019 Accepted: 02 September 2019

Published: 18 September 2019

Citation:

Cormier B, Batel A, Cachot J,

Bégout M-L, Braunbeck T, Cousin X and Keiter SH (2019) Multi-Laboratory Hazard Assessment of Contaminated

Microplastic Particles by Means of Enhanced Fish Embryo Test With the

Zebrafish (Danio rerio)

Front. Environ. Sci. 7:135.

doi: 10.3389/fenvs.2019.00135

\section{Multi-Laboratory Hazard Assessment of Contaminated Microplastic Particles by Means of Enhanced Fish Embryo Test With the Zebrafish (Danio rerio)}

\author{
Bettie Cormier ${ }^{1,2 \star}$, Annika Batel ${ }^{3}$, Jérôme Cachot $^{2}$, Marie-Laure Bégout ${ }^{4}$, \\ Thomas Braunbeck ${ }^{3}$, Xavier Cousin ${ }^{5,6}$ and Steffen H. Keiter ${ }^{1 *}$ \\ ${ }^{1}$ Man-Technology-Environment Research Centre, School of Science and Technology, Örebro University, Örebro, Sweden, \\ ${ }^{2}$ University of Bordeaux, EPOC UMR CNRS 5805, Pessac, France, ${ }^{3}$ Aquatic Ecology and Toxicology Group, Center for \\ Organismal Studies, University of Heidelberg, Heidelberg, Germany, ${ }^{4}$ Laboratoire Ressources Halieutiques, IFREMER, \\ L'Houmeau, France, ${ }^{5}$ IFREMER, L3AS, UMR MARBEC, Palavas-les-Flots, France, ${ }^{6}$ UMR GABI INRA, AgroParisTech, \\ University Paris-Saclay, Jouy-en-Josas, France
}

As wide-spread pollutants in the marine environment, microplastics (MPs) have raised public concern about potential toxic effects in aquatic organisms, and, among others, MPs were suspected to act as a vector for organic pollutants to biota. The purpose of the present study was to investigate effects by three model pollutants, oxybenzone (BP3), benzo[a]pyrene (BaP), and perfluorooctane sulfonate (PFOS) adsorbed to polyethylene MPs on the basis of a standard assay, the acute fish embryo toxicity test (FET; OECD TG 236) with zebrafish (Danio rerio) supplemented by additional endpoints such as induction of ethoxyresorufin-O-deethylase (EROD) activity, modification of cyp1a gene transcription and changes in larval swimming behavior. FET assays were performed in three laboratories using slightly different husbandry and exposure conditions, which, however, were all fully compatible with the limits defined by OECD TG 236. This allowed for testing of potential changes in the FET assay due to protocol variations. The standard endpoints of the FET (acute embryotoxicity) did not reveal any acute toxicity for both virgin MPs and MPs spiked with BP3, BaP, and PFOS. With respect to sublethal endpoints, EROD activity was increased after exposure to MPs spiked with BP3 (3h pulse) and MPs spiked with BaP (96h continuous exposure). Cyp1a transcription was increased upon exposure to MPs spiked with BP3 or BaP. For the selected combination of MPs particles and contaminants, the basic FET proved not sensitive enough to reveal effects of (virgin and spiked) MPs. However, given that the FET can easily be supplemented by a broad variety of more subtle and sensitive endpoints, an enhanced FET protocol may provide a relevant approach with developmental stages of a vertebrate animal model, which is not protected by current EU animal welfare legislation (Directive EU 2010/63).

Keywords: fish embryotoxicity test (FET), swimming behavior, EROD, cyp1a, perfluorooctane sulfonate, benzo[a]pyrene, oxybenzone 


\section{INTRODUCTION}

Plastics have become an indispensable part of our daily life and yield important societal benefits (Andrady and Neal, 2009). Due to poor waste management, however, large portions of the manufactured plastic end up in the oceans and will eventually show up as macroplastics ( $>5 \mathrm{~mm}$ ) or microplastics (MPs), i.e., particles between $1 \mu \mathrm{m}$ and $5 \mathrm{~mm}$ in size (Jambeck et al., 2015). The latter consist of either plastic granules designed for purpose in e.g., cosmetics or small plastic fragments derived from the breakdown of macroplastics (Derraik, 2002; Thompson et al., 2004). MPs of both types are considered as a potential threat for aquatic ecosystems (Thompson et al., 2009; Cole et al., 2011).

Plastic materials are not restricted to the polymers themselves, but often also contain numerous additives designed to produce their specific physicochemical properties and to protect MPs from damage by heat, UV light, oxidative processes as well as from microbiological degradation (Andrady, 2011). Many additives are per se known as putative toxicants and, upon release from plastic materials, they may potentially cause adverse health effects (Bakir et al., 2014). MPs particles have been shown to adsorb significant amounts of organic pollutants from the surrounding environment (Mato et al., 2001; Rios et al., 2007; Barnes et al., 2009; Koelmans et al., 2016), and weathering processes as well as mechanical fragmentation of MPs lead to smaller particles and may increase the specific reactive surface area of particles and thus facilitate further the sorption of pollutants (Teuten et al., 2007; Koelmans et al., 2013; Lee et al., 2014). Under both laboratory and field conditions, different MPs have been shown to adsorb various classes of organic pollutants such as per- and polyfluorinated compounds, polycyclic aromatic hydrocarbons (PAHs), polychlorinated biphenyls (PCBs), pesticides and personal care products (Rochman et al., 2013a,b; Ziccardi et al., 2016), and the relative contribution of MPs to the transfer of organic pollutants to biota has for long been subject to controversy (Bakir et al., 2016; Koelmans et al., 2016; Lohmann, 2017).

Polyethylene (PE) represents the polymer with the greatest global production for plastic manufacturing, and-for its highly diverse uses- $\mathrm{PE}$ contains a wide variety of additives. PE was selected as experimental MPs for the present study because of its predominance in marine ecosystem (Andrady, 2011). As a polymer, PE per se is supposed to bear a relatively low hazard (Lithner et al., 2011; Karami et al., 2017); however, due to its physicochemical properties and high abundancy in aquatic environments, PE MPs have a high potential to adsorb and transfer organic pollutants (Rochman et al., 2013a; Wang F. et al., 2015). Together, chemical contaminants and PE may represent a higher risk to aquatic organisms compared to other polymers (Karami et al., 2017).

Benzophenone-3 (oxybenzone, BP3) is commonly used as a UV-filter in cosmetics such as sunscreens, but also as a light stabilizer in plastics such as PE. In addition, BP3 has repeatedly been reported to act as an endocrine disrupting chemical interfering with reproduction and sex hormone signaling in fish and mammals (Kim and Choi, 2014; Kinnberg et al., 2015; Rodríguez-Fuentes et al., 2015). BP3 shows low degradation rates in surface waters (Kim and Choi, 2014) and-due to its lipophilicity (log Kow 4.0) - may bioaccumulate in biota.

Benzo[a]pyrene $(\mathrm{BaP})$ is formed by incomplete combustion of organic materials (Collins et al., 1991) and has become the most frequently studied representative of carcinogenic PAHs and a model molecule for the investigation of PAHs as inducers of aryl hydrocarbon receptor (AhR)-based metabolization pathways. BaP is ubiquitously distributed in coastal and offshore environments (Antunes et al., 2013; Liu et al., 2015; Châtel et al., 2017), and PAHs including BaP are known to adsorb at high rates to different types of MPs in seawater, particularly to PE (Rochman et al., 2013a; Ziccardi et al., 2016; Schönlau et al., 2019). Furthermore, BaP adsorbed to MPs has been documented to be transferred via trophic transfer to biota (Batel et al., 2016, 2018; Bour et al., 2018; O’Donovan et al., 2018; Pittura et al., 2018).

Given its wide distribution, perfluorooctane sulfonate (PFOS) has attracted most attention among perfluorinated substances, since it represents the main perfluorinated alkylated compounds detected in aquatic environments (Keiter et al., 2016). PFOS is an extremely persistent fluorinated pollutant that does not hydrolyze, photolyase or biodegrade. PFOS is also known to be toxic and bioaccumulative and undergo extensive transportation across all environmental media. As a consequence, PFOS has been documented in soil, sediment, sludge, and water bodies (Giesy and Kannan, 2002). Since, in ocean surface waters, PFOS and its precursors have been estimated at 235-1,770 metric tons (Paul et al., 2009), PFOS was added to the list of the Stockholm convention on Persistent Organic Pollutants in 2010.

A wide array of bioassays has been developed to assess the toxicity of chemicals or environmental samples. Given that early developmental stages of vertebrates that depend on the use of yolk are considered non-protected according to current European legislation on the protection of animals used for scientific purposes (EU, 2010; Strähle et al., 2012) and that fish embryonic stages have been demonstrated to be equally sensitive to chemical pollutants as intact fish (Nagel, 2002; Braunbeck et al., 2005, 2015; Lammer et al., 2009; Belanger et al., 2013). The fish embryo acute toxicity test (FET) has been designed as an alternative to conventional fish acute toxicity testing [e.g., OECD TG 203; (OECD, 1992)] and has been approved as OECD Test Guideline 236 (OECD, 2013). According to the guideline, the FET has successfully been applied to a wide range of substances exhibiting diverse modes of action, solubilities, volatilities, and hydrophobicities. However, given the particulate nature of MPs, the question arises whether the FET might equally be suited for the assessment of MPs toxicity. In fact, there are major differences between soluble pollutants and discrete objects such as MPs including, e.g., dispersion, homogeneity, localized desorption events of additives or adsorbed pollutants. The purpose of the present study was, therefore, to use the standard FET procedure to document the acute toxicity of MPs and MPs spiked with selected organic pollutants (BP3, BaP, and PFOS). Since OECD TG 236 provides a general framework and allows for substantial flexibility in test conditions, the present study was designed to test for potential differences in FET sensitivity toward MPs due to, e.g., variability in fish pre-conditioning, dark-light scenarios 
or exposure conditions. Protocols used by the three laboratories involved in the present comparative study presented some differences but were all within the limits defined by OECD TG 236. In order to enhance resolution and sensitivity of FET, we also monitored additional endpoints such as EROD activity and cyp $1 a$ transcription as well as larval swimming behavior to reveal potential sublethal effects.

\section{MATERIALS AND METHODS}

\section{Materials and Chemicals}

Polyethylene (PE; order no. MPP-635G) with a size range of $11-13 \mu \mathrm{m}$ and a density of $0.96 \mathrm{~kg} / \mathrm{m}^{3}$ purchased from Micro Powders (New York, USA) was kindly provided within the JPI Oceans project EPHEMARE as a dry powder by Marina Albentosa (Instituto Español de Oceanografía, Centro Oceanografico de Murcia, Spain). Benzo[a]pyrene (BaP; CAS 50-32-8; purity $\geq 96 \%$ ), benzophenone-3 [(2hydroxy-4-methoxyphenyl)-phenylmethanone, BP3; CAS 13157-7; purity $\geq 98 \%]$ and PFOS $(1,1,2,2,3,3,4,4,5,5,6,6,7,7,8,8,8$ heptadecafluorooctane-1-sulfonic acid; CAS 2785-37-3; purity $\geq$ 98\%) were purchased from Sigma Aldrich (Stockholm, SE). All other chemicals and reagents were purchased at the highest purity available from Sigma-Aldrich, unless stated otherwise.

\section{Spiking of Microplastic Particles}

Setups for the spiking, e.g., MPs and chemical concentrations were previously determined with preliminary experiments in order to determine all parameters to reach aimed concentrations, based on fish toxicity data, e.g., BP3 (Blüthgen et al., 2012; Paredes et al., 2014); BaP (Weigt et al., 2011) and PFOS (Yamashita et al., 2005). Preliminary studies demonstrated that to minimize loss of chemicals, PFOS exposure has to be prepared in polypropylene bottles (Lamaplast; Sesto San Giovanni, Italy), while for $\mathrm{BaP}$ and $\mathrm{BP} 3$, glass bottles (Thermo Scientific, Lund, $\mathrm{SE})$ were the most efficient to avoid loss of compound.

According to the pretests, for the sorption of $\mathrm{BP} 3$ and $\mathrm{BaP}$ to PE, $125 \mathrm{~g} / \mathrm{L}$ PE were added in $400 \mathrm{~mL}$ septa bottles (Thermo Scientific, Lund, SE) and bottles were filled to the maximum with double-deionized water, to avoid gas headspace in the bottle, and so avoid volatilization of compound. $\mathrm{BP} 3$ and $\mathrm{BaP}$ concentrations in the solutions were 20 and $2,500 \mu \mathrm{g} / \mathrm{L}$, respectively. For the sorption of PFOS on PE, $50 \mathrm{~g} / \mathrm{L}$ of plastic were weighed into $1 \mathrm{~L}$ polypropylene bottles (Lamaplast; Sesto San Giovanni, Italy) filled with double-deionized water and PFOS was added to a final concentration of $20 \mathrm{mg} / \mathrm{L}$. All bottles were placed on a rotary shaker for $48 \mathrm{~h}(\mathrm{BP} 3$ and $\mathrm{BaP}$ ) or 7 days (PFOS) at 20 $\mathrm{rpm}$ and at room temperature $\left(20 \pm 1^{\circ} \mathrm{C}\right)$. Based on preliminary experiments, after $48 \mathrm{~h}$, concentrations of $\mathrm{BaP}$ and $\mathrm{BP} 3$ adsorbed on MPs were higher than samples shaken for more than $48 \mathrm{~h}$ due to volatilization of compound, and an increase of the adsorption to glass bottle. While, for PFOS, the sorption time of 7 days was maintained because of the lowest standard deviation of the results and the highest concentration of PFOS adsorbed on particles, compared to other time points.

\section{Chemical Analyses and Quality Assurance/Quality Control (QA/QC)}

Concentrations of chemicals (BP3, BaP, and PFOS) were measured in corresponding spiked MPs as well as in virgin MPs to determine background contamination of each chemical.

After filtration of the MP preparations with a funnel equipped with a $1 \mu \mathrm{m}$ Whatman ${ }^{\circledR}$ glass microfiber filter (GE Healthcare Life Sciences; Uppsala, SE), the filters were rinsed with double deionized water and dried by vacuum evaporation on a ceramic funnel.

The analysis of BP3 was performed by Eurofins Germany (Pforzheim, DE) by using an $0.3 \mathrm{~g}$ aliquot of the sample spiked with internal standards (i.e., 3,4,5,6pentadeuteriobenzoic acid, 1-bromo-4-phenylbenzene, 1,2,3,4,5,6,7,8-octadeuterionaphthalene, 1,2,3,4,5-pentachloro6-(2,3,4,5,6-pentachlorophenyl)benzene, and 1,2,3,4,5,6,7,8,9,10decadeuteriophenanthrene) and concentrated with a factor of 10. The samples were extracted with a 1:1 solvent mixture of ethyl acetate and cyclohexane. Additionally, an external calibration standard and a blank sample were prepared. The extracts were measured with GC/MS/MS, electron impact ionization (GC: Agilent7890 A, MS/MS: Agilent 7000 multiple-reaction monitoring mode, Agilent Technologies, Kista, SE) using a split-less injection of $2 \mu \mathrm{l}$ (column DB5-MS, $30 \mathrm{~m} \times 0.25 \mathrm{~mm} \times 0.25 \mu \mathrm{m}$ ). Identification and quantification were performed against the retention time and the external calibration using the BP3specific selected reaction monitoring (one quantifier and one qualifier).

$\mathrm{BaP}$ analysis has been conducted according to Larsson et al. (2013): MPs were extracted in hexane ( $\geq 98 \%$, SupraSolv; Merck, Darmstadt, DE) after addition of an internal standard (500 ng BaP D12 in toluene; Chiron, Tuttlingen, DE; prepared standard: $10 \mathrm{ng} / \mu \mathrm{l}$ in toluene) by sonication and centrifugation at 2,000 rpm. Extracts were filtered through fiberglass and transferred to toluene (purity 96\%, SOLVECO; Rosersberg, SE). GC vials for analysis were filled with $100 \mathrm{ng}$ recovery standard perylene D12 (Chiron; $2 \mathrm{ng} / \mu \mathrm{l}$ in toluene, $50 \mu \mathrm{l}$ added) and $500 \mu \mathrm{l}$ of extract. The sample volume was reduced to $500 \mu \mathrm{l}$ using a nitrogen stream. Concentrations of $\mathrm{BaP}$ were quantified using a Micromass Autospec Ultima high-resolution GC/MS system, separation on a 30 meters $(0.25 \mathrm{~mm}$ internal diameter, $25 \mu \mathrm{m}$ film thickness) DB-5MS column (J\&W Scientific, Folsom, USA). Procedure blanks were included in all batches. Target $\mathrm{BaP}$ was quantified by using a five-point calibration curve. Relative standard deviation of the relative response factor values was $<15 \%$ for PAHs. Quantification standard replicates were analyzed after every tenth sample. Concentrations of $\mathrm{BaP}$ were calculated by use of the internal standard method. The limit of detection (LOD) was defined as mean concentration in blanks plus three times the standard deviations and was $5 \mathrm{pg} / \mathrm{g}$. Samples which had concentrations exceeding the range of the calibration curve were diluted and reanalyzed. Procedure blanks were included in all batches.

Chemical analysis of PFOS has been conducted according to Eriksson et al. (2016): PFOS (linear and isomers) adsorbed to MPs were extracted in methanol ( $>99.9 \%$ purity, Fisher 
TABLE 1 | Husbandry conditions of zebrafish in the three participating laboratories.

\begin{tabular}{|c|c|c|c|c|c|c|c|c|}
\hline \multirow[t]{2}{*}{ Laboratory } & \multirow[t]{2}{*}{ Day/night cycle [h] } & \multicolumn{3}{|c|}{ Water parameters } & \multirow[t]{2}{*}{ Group sizes } & \multirow[t]{2}{*}{ Tank size } & \multirow[t]{2}{*}{ Zebrafish strain } & \multirow[t]{2}{*}{ Artificial food } \\
\hline & & Temperature & $\mathrm{pH}$ & Conductivity & & & & \\
\hline Örebro University & $14 / 10$ & $26 \pm 1^{\circ} \mathrm{C}$ & $7.2 \pm 0.2$ & $380 \pm 50 \mu \mathrm{S}$ & $100 \pm 10$ & $60 \mathrm{~L}$ & $A B$ & TetraMin \\
\hline IFREMER & $14 / 10$ & $27 \pm 1^{\circ} \mathrm{C}$ & $7.8 \pm 0.2$ & $485 \pm 130 \mu \mathrm{S}$ & $28 \pm 5$ & $10 \mathrm{~L}$ & TU & Inicio + Biomar \\
\hline Heidelberg University & $16 / 8$ & $26 \pm 1^{\circ} \mathrm{C}$ & $7.2 \pm 0.1$ & $360 \pm 20 \mu S$ & $\geq 150$ & $160 \mathrm{~L}$ & West-aquarium & TetraMin \\
\hline
\end{tabular}

Provider for flake food: TetraMin (Tetra, Sweden), Tetra (Melle, Germany), Inicio + 0.5 mm (BioMar, France).

Scientific) by ultra-sonication following by centrifugation $(7,000$ $\mathrm{rpm}$ ). Extracts were filtered using a $5 \mathrm{~mL}$ PE syringe (NormJect ${ }^{\circledR}$; Henke Sass Wolf, Tuttlingen, DE) with a filter of $0.2 \mu \mathrm{m}$ (13 mm, $0.2 \mu \mathrm{m}$ AcrodiscGHP; Pall, Dreieich, DE). LC vials were prepared with $2 \mathrm{ng}$ of recovery standard (mass-labeled PFOS). Samples were diluted 100 times using 40\% methanol (v/v) and $60 \%$ ammonium acetate (v/v). Analysis was performed on an Acquity UPLC system coupled to a Xevo TQ-S quadrupole MS (Waters, Milford, USA). A guard column (PFC isolator, Waters) was inserted between the pump and the injector to prevent contamination from the system. PFOS were separated on $100 \mathrm{~mm}$ Acquity BEH C18 column $(2.1,1.7 \mathrm{~mm})$ using methanol and water as mobile phases, both with $2 \mathrm{mM}$ ammonium acetate. Quantification of total PFOS was performed by summarization of linear PFOS and individual branched PFOS calculated against an external calibration curve using technical PFOS as standard. Recoveries were assessed using labeled internal standards. The mean recoveries of labeled PFOS internal standards was $83-96 \%$. The LOD was calculated as above was $10 \mathrm{pg} / \mathrm{g}$. Procedure blanks were included in all batches.

\section{Zebrafish Husbandry and Egg Production}

Fish husbandry in the three participating laboratories conditions fully complied with OECD TG 236 (Westerfield, 2007; OECD, 2013), but maintenance of adult zebrafish (Danio rerio) differed slightly regarding dark/light cycles, size of the rearing tanks, size of heterosexual groups, and water conditions including temperature, $\mathrm{pH}$ and conductivity (Table 1). In each laboratory, feeding was twice daily ad libitum with commercially available artificial diets and freshly hatched brine Artemia nauplii. Constant filtering or permanent flow-through conditions guaranteed that ammonia, nitrite, and nitrate were kept below detection limits $(5,1$, and $140 \mathrm{mg} / \mathrm{L}$, respectively). Zebrafish eggs were collected according to OECD TG 236 (OECD, 2013).

\section{Toxicity Testing}

\section{Zebrafish Embryo Acute Toxicity Test}

The acute hazard potential of MPs and contaminated MPs was determine on the basis of the FET guideline (OECD 236) which provides a framework for the test, but allows for some variation in parental fish breeding and exposure conditions. In order to analyze the potential impact of minor modifications of the protocol, the three laboratories participating in the present comparative study performed the test with minor differences in the rearing temperature and the dark/light cycle of the parent fish, as well as in the volume of vessels used and the shaking of
TABLE 2 | Overview about the test conditions and solutions for the zebrafish embryo toxicity test used by the three different laboratories.

\begin{tabular}{|c|c|c|c|}
\hline & Örebro University & IFREMER & $\begin{array}{l}\text { Heidelberg } \\
\text { University }\end{array}$ \\
\hline MPs size & \multicolumn{3}{|c|}{ PE 11-13 $\mu \mathrm{m}$} \\
\hline MPs concentrations & $10,100 \mathrm{mg} / \mathrm{L}$ & $10 \mathrm{mg} / \mathrm{L}$ & $100 \mathrm{mg} / \mathrm{L}$ \\
\hline Exposure vessels & \multicolumn{3}{|c|}{ Glass vials } \\
\hline Vessel volumes & $100 \mathrm{~mL}$ & $60 \mathrm{~mL}$ & $2 \mathrm{~mL}$ \\
\hline Solution volumes & $20 \mathrm{~mL}$ & $10 \mathrm{~mL}$ & $1.2 \mathrm{~mL}$ \\
\hline Embryos per assay & 5 & 20 & $20^{\star}$ \\
\hline $\begin{array}{l}\text { Shaking during } \\
\text { exposure }\end{array}$ & No shaking & No shaking & $\begin{array}{l}\text { Gentle } \\
\text { agitation }\end{array}$ \\
\hline Positive control & \multicolumn{3}{|c|}{ 3,4-Dichloraniline (4 mg/L) } \\
\hline Temperature & $26 \pm 1^{\circ} \mathrm{C}$ & $27 \pm 1^{\circ} \mathrm{C}$ & $25 \pm 1^{\circ} \mathrm{C}$ \\
\hline Dark/light rhythm & $10 / 14 h$ & $10 / 14 h$ & $8 / 16 h$ \\
\hline
\end{tabular}

*One embryo per $2 \mathrm{~mL}$ flat bottom argon glass vials (NeoLab, Heidelberg, DE), which were placed in 20 wells of a 24-well plate $(n=20$; TPB, Trasadingen, Switzerland). Each glass vial was covered with a cap (unknown composition, caps were washed before use, but did not get into contact with the medium) to prevent evaporation.

the test solutions (Table 2); care was taken that the protocols of all three laboratories were clearly within the limits set by OECD TG 236. All other parameters of the tests themselves were identical and followed OECD TG 236.

Embryo exposure started at a maximum of 4 hours postfertilization (hpf) and was performed in glass containers covered with lids, under semi-static conditions with a daily renewal of exposure medium. Exposures were performed using either MPs or MPs spiked with one pollutant at 10 and/or $100 \mathrm{mg} / \mathrm{L}$ (Table 3). An additional treatment, later called 3POPs, was an even mixture of MPs spiked with BP3, BaP, and PFOS, also used at a final concentration of MPs of 10 or $100 \mathrm{mg} / \mathrm{L}$. The exposure design included negative controls (virgin MPs) and positive controls (water-borne 3,4-dichloraniline, $4 \mathrm{mg} / \mathrm{L}$ ). In each laboratory, all exposures were performed in triplicate. Embryos were analyzed every day for lethal (OECD, 2013) and sublethal effects as well as hatching rate.

As an additional control, the three pollutants (BP3, BaP, and PFOS) were also tested via waterborne exposure at final concentrations equivalent to complete desorption in the case of an exposure to $10 \mathrm{mg} / \mathrm{L}$ of MPs. Actual concentrations for BP3, $\mathrm{BaP}$, and PFOS were $0.8,170$, and $700 \mathrm{ng} / \mathrm{L}$, respectively. For waterborne exposure, DMSO was used as a solvent at a final concentration of $0.01 \%$; as a solvent control, $0.01 \%$ DMSO was run as an additional negative control. 
TABLE 3 | Exposure scenarios tested by the three laboratories for MPs, adsorbed MPs [MP + pollutant(s)] and pollutants alone.

\begin{tabular}{|c|c|c|c|c|c|c|c|c|c|c|}
\hline & 10 mg/L MP & 100 mg/L MP & MP & $\mathrm{MP}+\mathrm{BP} 3$ & $\mathrm{MP}+\mathrm{BaP}$ & $\mathrm{MP}+\mathrm{PFOS}$ & $M P+3 P O P s$ & BP3 & BaP & PFOS \\
\hline Örebro University & $\times$ & $\times$ & $x$ & $\times$ & $\times$ & $x$ & $\times$ & $x$ & $\times$ & $\times$ \\
\hline IFREMER & $\times$ & & $\times$ & $\times$ & $\times$ & $\times$ & $\times$ & - & - & - \\
\hline Heidelberg University & & $x$ & $x$ & $x$ & $\times$ & $x$ & - & - & - & - \\
\hline
\end{tabular}

TABLE 4 | Concentrations of MPs and pollutants (mean \pm SD) in solution and the resulting concentration of the pollutants on the PE particles $(n=1$ for BP3 and $n=3$ for BaP and PFOS).

\begin{tabular}{|c|c|c|c|}
\hline & \multicolumn{2}{|c|}{ Preparation solution } & \multirow{2}{*}{$\begin{array}{l}\text { Pollutant conc. } \\
\text { spiked to MPs }(\mu \mathrm{g} / \mathrm{g}\end{array}$} \\
\hline & PE (g/L) & Pollutants $(\mu \mathrm{g} / \mathrm{L})$ & \\
\hline BP3 & 125 & 20 & 0.08 \\
\hline $\mathrm{BaP}$ & 125 & 2,500 & $16.87 \pm 0.22$ \\
\hline PFOS & 50 & 20,000 & $70.22 \pm 12.41$ \\
\hline
\end{tabular}

\section{In vivo EROD Assay}

In vivo ethoxyresorufin-O-deethylase (EROD) induction in zebrafish embryos was determined according to Kais et al. (2018): Tests was performed at $96 \mathrm{hpf}$ embryos, which were either incubated for $96 \mathrm{~h}$ with $100 \mathrm{mg} / \mathrm{L}$ of MPs $(0-96 \mathrm{~h})$ with daily exchange of medium as previously described, or for a $3 \mathrm{~h}$ short-term exposure (93-96h) with $100 \mathrm{mg} / \mathrm{L}$ of MPs. In short, 20 embryos per treatment group and replicate were washed twice for $5 \mathrm{~min}$ using dilution water and incubated for $20 \mathrm{~min}$ in $0.6 \mathrm{mg} / \mathrm{L}$ 7-ethoxyresorufin (Sigma Aldrich, Deisenhofen, Germany). After anesthesia with $0.016 \%$ tricaine (MS-222), embryos were mounted left side down in $1 \%$ low-melting agarose (SeaKem HGT Agarose; Cambrex BioScience, Rockland, USA) supplemented with $0.016 \%$ tricaine. The fluorescence by resorufin formed from 7-ethoxyresorufin via Cypla catalysis was measured under a Nikon ECLIPSE 90i epifluorescence microscope (Nikon Instruments; Tokyo, Japan) equipped with a $10 \times$ Nikon CFI Plan Fluor water immersion objective (NA 0.17 , WD $16.0 \mathrm{~mm}$ ) at an excitation of $560 \pm 20 \mathrm{~nm}$ (Texas Red HYQ filter) and an emission of $630 \pm 30 \mathrm{~nm}$ with a dichroic beam splitter of $595 \mathrm{~nm}$. A Nikon DS-Ri-1 camera was used for imaging. Image processing was performed with the NIS-Elements 4.0 imaging software (Nikon Instruments). As a positive control, embryos were incubated at $96 \mathrm{hpf}$ for $3 \mathrm{~h}$ in 75 $\mu \mathrm{g} / \mathrm{L} \beta$-naphthoflavone. Three replicates were run for each test and treatment group $(n=3 \times 20)$.

\section{Cyp1a Gene Transcription Analysis}

For analyzes of cypla induction, $96 \mathrm{hpf}$ embryos $(n=15$ per exposure group) were exposed for $3 \mathrm{~h}$ to MPs as described above. Exposures were performed in triplicate $(n=3 \times 15)$. Ninety-six hours post-fertilization embryos incubated for $3 \mathrm{~h}$ in $75 \mu \mathrm{g} / \mathrm{L} \beta$-naphthoflavone (Boehler et al., 2018) were used as a positive control. After exposure, embryos were euthanatized in $500 \mathrm{mg} / \mathrm{L}$ benzocaine, thoroughly rinsed in deionized water and stored in RNALater (Qiagen, Les Ulis, France). Prior to extraction, RNALater was removed, and embryos were placed in a lysis buffer (Qiagen) before being mechanically disrupted using Beadblaster (Benchmark Scientific, Dutscher, France). The total RNA extraction followed the protocols of the RNeasy Plus Universal Mini Kit (Qiagen). Quality and quantity of the extracts were checked using electrophoresis migration and spectrophotometric dosing. Subsequently, cDNA was synthesized from $2 \mu \mathrm{g}$ of the total RNA, using $2 \mu \mathrm{l}$ of Superscript III Reverse Transcriptase (Invitrogen, Fisher Scientific, Illkirch, France) according to the manufacturer's protocol in a final volume of $21 \mu$ l. Prior to analysis, all cDNA was diluted $5 \times$ in Milli- $\mathrm{Q}$ water. The qPCR experiments were run in a final volume of $20 \mu \mathrm{L}$, including an optimized primer concentration ranging between 300 and $600 \mathrm{nM}$ (Eurofins, Ebersberg, Germany) and 2X Fast SYBR Green Master Mix (Applied Biosystems, Fisher Scientific, Illkirch, France). The amplification protocol used was as follows: initial denaturation $\left(20 \mathrm{~s}\right.$ at $95^{\circ} \mathrm{C}$ ) followed by 40 cycles of $3 \mathrm{~s}$ at $95^{\circ} \mathrm{C}$ and $30 \mathrm{~s}$ at $60^{\circ} \mathrm{C}$. Technical triplicates were run for each biological replicate. The analysis software Relative Expression Software Tool (REST; Pfaffl, 2001; Pfaffl et al., 2002) automatically calculated fold changes in expression relative to negative controls (unexposed embryos) using the 3 most stable references genes between all groups, and combined them into an index via the free access BestKeeper software (Pfaffl et al., 2004). Reference genes were $g 6 p d$, $a c t b 1$, and rpl13a. Sequences and characteristics of all primers used are listed in Table S1.

\section{Larval Behavior}

Larval behavior was monitored at $120 \mathrm{hpf}$ using the larval photomotor response (LPMR) test as described by Vignet et al. (2014). The morning before the LPMR, single embryos were individually transferred into one well of a 24-well plate (Krystal 24, opaque wall and clear bottom microplate, Dutscher), and plates were transferred to an enlighten incubator at the same temperature as in the testing room. Plates were successively placed into DanioVision ${ }^{\mathrm{TM}}$ (Noldus, Wageningen, NL) in the dark for $10 \mathrm{~min}$ of acclimation before the LPMR test which included the following 5-min steps: Light on-1 (LON1, 70 lux), Light off (LOFF, $<1$ lux) and Light on -2 (LON2, 70 lux) with constant infra-red light maintained during video recording. Distance traveled $(\mathrm{cm})$ was recorded and summed for each 5min step. Four embryos from each treatment were used in each plate $(n=6)$ to avoid potential bias. Embryos with tracking issues were removed resulting in 16-24 embryos analyzed per treatment. After LPMR recording, embryos were anesthetized with benzocaine $(50 \mathrm{mg} / \mathrm{L})$ and photographed in lateral view. 
Larval standard length was measured using ImageJ (Schneider et al., 2012).

\section{Statistics}

For both the FET and the in vivo EROD assay, three independent runs were performed, and data were tested for normality with the Shapiro-Wilk and Kolmogorov-Smirnov tests. If data were normally distributed, one-way analysis of variance (ANOVA) was run in combination with a post-hoc Dunnett's test; otherwise, a non-parametric Kruskal-Wallis, Mann-Whitney U or Wilcoxon's matched-pairs tests were used for statistical comparison.
Data were first analyzed for differences between runs (biological replicates). Since there were no significant differences between independent runs, single data sets were merged for each laboratory, and tests on different exposure groups were performed.

In the case of LPMR, a repeated-measure ANOVA was performed to take into account the three successive periods of the test.

A $p$-value of 0.05 was considered statistically significant for all analyses. Graphical illustrations and statistical tests were performed with Sigma Plot 12.5 (Jandel-Systat, Erkrath, Germany).

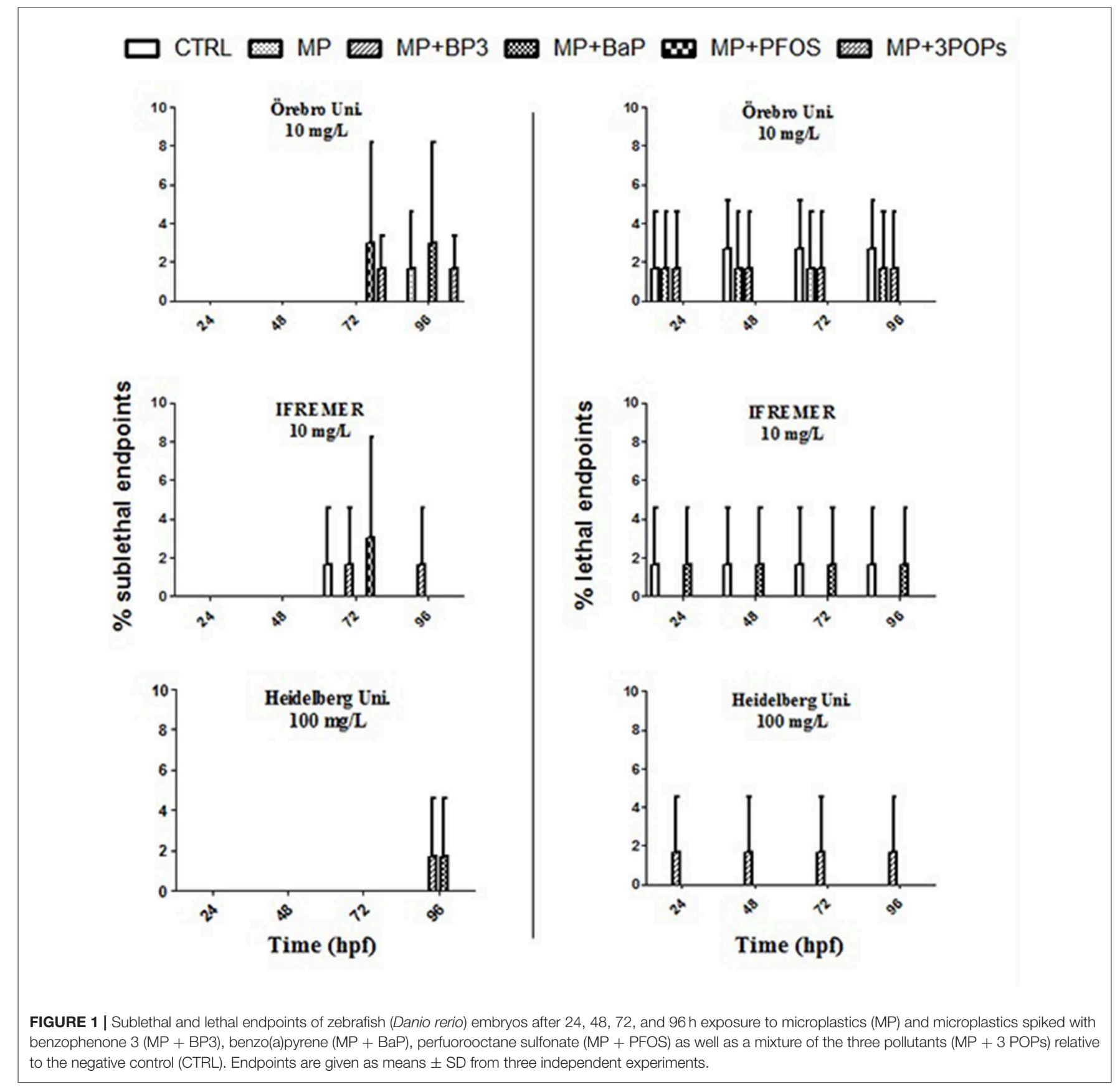




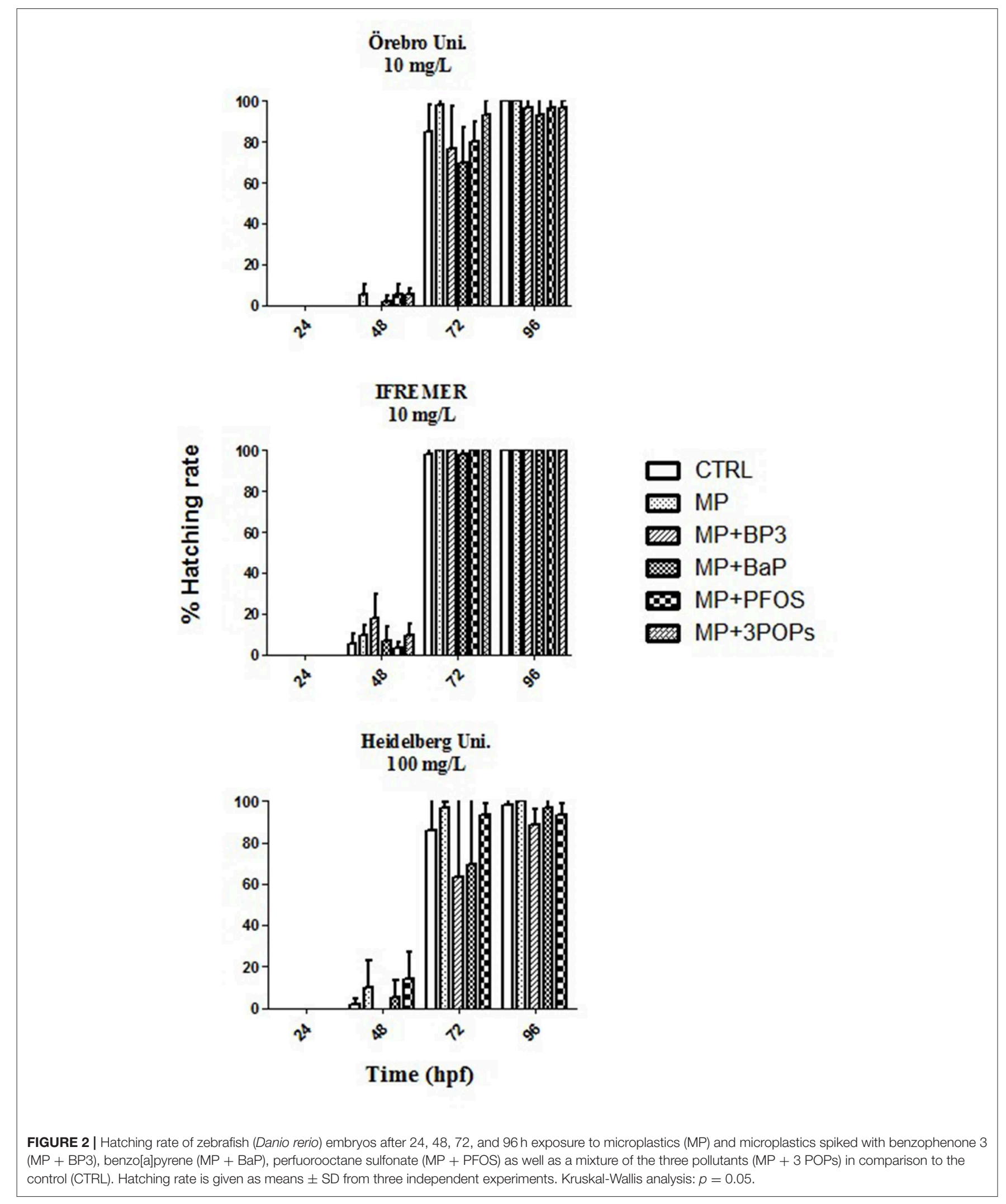



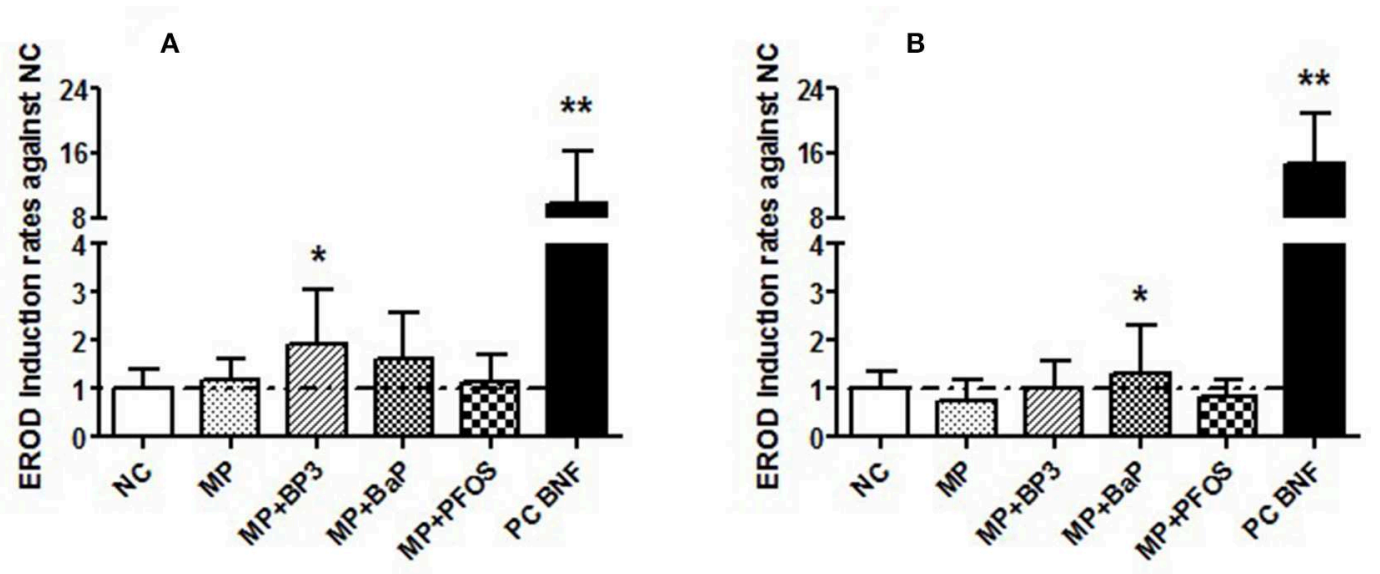

FIGURE 3 | EROD activity in $96 \mathrm{~h}$ old zebrafish (Danio rerio) embryos exposed to microplastic (MP) and microplastic spiked with benzophenone 3 (MP + BP3), benzo[a]pyrene (MP + BaP), perfuorooctane sulfonate (MP + PFOS), and $\beta$-naphthoflavone as a positive control (PC BNF) after $3 \mathrm{~h}$ pulse (A) or $96 \mathrm{~h}$ continuous exposure (B). EROD activities are given relative to negative controls $(\mathrm{NC})$ as means $\pm \mathrm{SD}\left(n=3\right.$; ANOVA on ranks: ${ }^{*} p<0.05$, $\left.{ }^{\star *} p<0.01\right)$.

\section{RESULTS}

\section{Background Contamination and Spiking of Microplastics by the Model Pollutants}

Background contamination by all three pollutants was measured on virgin microplastics. Results showed no presence of BP3 $(<0.05 \mathrm{ng} / \mathrm{g}, \mathrm{LOD})$ and $\mathrm{BaP}(<5 \mathrm{pg} / \mathrm{g}, \mathrm{LOD})$. However, PFOS was found on the PE particles at a concentration of 12.1 $\pm 3.5 \mathrm{pg} / \mathrm{g}$. This background concentration was taken into consideration when analyzing concentrations of PFOS adsorbed to MPs particles.

Chemical quantification of the three pollutants on PE showed that each pollutant has specific sorption efficiencies: $51 \%$ (BP3), $84 \%(\mathrm{BaP})$, and $18 \%$ (PFOS) of the total amount of the pollutants in the solution adsorbed to the $\mathrm{PE}$ particles, respectively. Concentrations of $\mathrm{BP} 3, \mathrm{BaP}$ and PFOS on MPs are reported in Table 4.

\section{Embryotoxic and Teratogenic Effects}

Embryotoxicity and teratogenicity of the selected pollutants diluted in water and DMSO without MPs were evaluated using a FET supplemented by various sublethal endpoints. The results did not show any significant effect (lethal, sublethal effects as malformations and hatching rate) between the negative control and the exposed individuals $(p>0.05)$.

The spiked MPs particles with BP3, BaP, and PFOS caused neither acute toxicity nor any teratogenic effects in the embryos using particle concentrations of 10 and $100 \mathrm{mg} / \mathrm{L}(p>0.05$; Figure 1). The examination of embryos exposed to the different MPs particles showed minor changes of the hatching rate at $72 \mathrm{hpf}$. Results were, however, statistically not different at any time point measured ( $p>0.05$; Figure 2). Moreover, measurements of the larvae standard length at $5 \mathrm{dpf}$ showed no significant differences between all conditions tested $(p>0.05$; Figure S1).

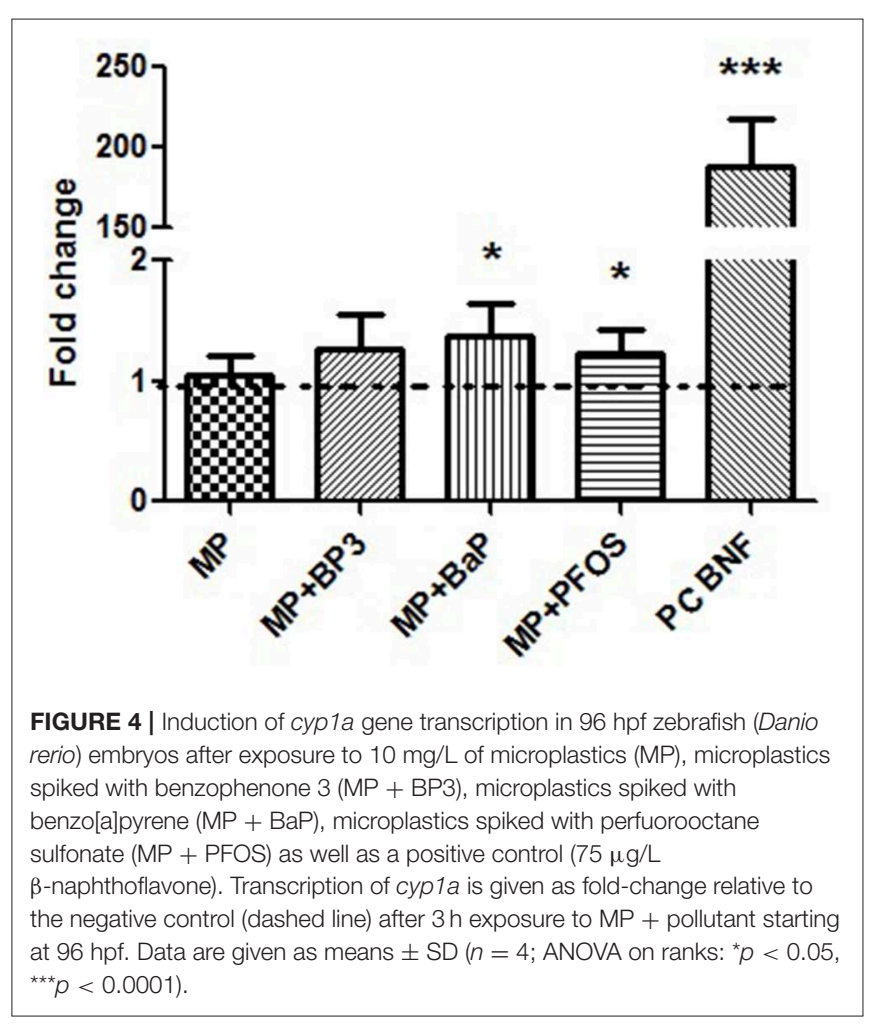

\section{EROD Activity}

EROD activity was measured in $96 \mathrm{hpf}$ embryos incubated to $100 \mathrm{mg} / \mathrm{L}$ of the different MPs for either a $3 \mathrm{~h}$ pulse or $96 \mathrm{~h}$ continuously. After the $3 \mathrm{~h}$ pulse (Figure 3A), only MPs spiked with BP3 (MP + BP3) induced a significant increase in EROD activity $(p<0.05)$, whereas after $96 \mathrm{~h}$ of continuous exposure to $\mathrm{MP}+\mathrm{BP} 3$ there was no induction of EROD activity (Figure 3B). In contrast, $96 \mathrm{~h}$ of continuous exposure to MPs spiked with $\mathrm{BaP}$ 


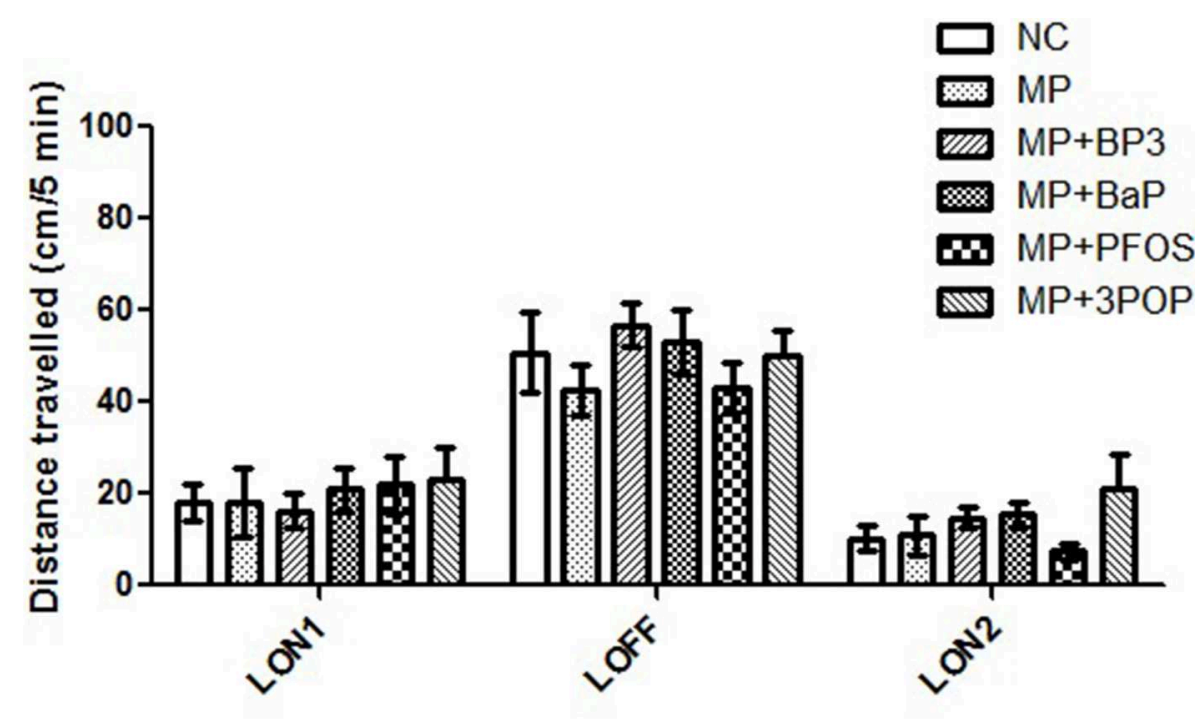

FIGURE 5 | Larval photomotor response in 5 days old zebrafish (Danio rerio) embryos after exposure to $10 \mathrm{mg} / \mathrm{L}$ of microplastics. Distance traveled over 5 min periods including two light-on periods (LON-1, LON-2) and one light off period (LOFF). Data are given as means \pm SD $(n=16-24$ larvae per treatment; repeated-measure ANOVA).

$(\mathrm{MP}+\mathrm{BaP})$ produced a significant increase in EROD activity $(p<0.05)$. MPs spiked with PFOS did not show any change in EROD activity whatever condition tested.

\section{Gene Transcription Analysis of Cyp1a}

Gene transcription of cyp $1 a$ was measured in zebrafish embryos after $3 \mathrm{~h}$ of exposure starting at 96 hpf. Figure 4 shows normalized fold-change in expression of cypla relative to negative controls. Virgin MPs particles did not show any significant change of cypla transcription $(p=0.569)$. In contrast, exposure to $\mathrm{MP}+\mathrm{BaP}$ and $\mathrm{MP}+\mathrm{PFOS}$ induced a mild, but significant increase in cypla transcription $(p=0.013$ and $p=0.039$, respectively), while in the case of $\mathrm{MP}+\mathrm{BP} 3$ the significance was just above the threshold $(p=0.059)$.

\section{Larval Behavior}

The larval photomotor response (LPMR) was performed at 5 $\mathrm{dpf}$ to monitor early behavioral disruption. Independent of the treatment, LPMR showed an increase in distance traveled during the dark phase (LOFF), if compared to both lights-on phases (LON1 and LON2; ANOVA $\left.F_{(2,321)}=38.07, p<0.001\right)$. Between treatments, however, there was no difference [repeated-measures ANOVA $F_{(15,281.98)}=0.96, p=0.496$; Figure 5].

\section{DISCUSSION}

The drastic increase in the amount of MPs in marine environments has raised concern about their potential impact on aquatic organisms (Rochman et al., 2013b; Karami et al., 2017; O'Donovan et al., 2018; Pittura et al., 2018). The adsorption of chemical pollutants from aquatic environments to MPs and the transfer to biota (Antunes et al., 2013; Bakir et al., 2016; Koelmans et al., 2016) is an additional important aspect of the potential toxicity of MPs (Batel et al., 2016; O’Donovan et al.,
2018). The present study was designed to evaluate the potential hazard of contaminated PE MPs for zebrafish embryos by using the standard protocol for the acute fish embryo toxicity test (OECD TG 236) as well as enhanced protocols supplemented by additional (sublethal) endpoints such as cytochrome P450 induction and behavioral changes. In comparison to MPs levels found in aquatic environments, the microplastics concentrations selected were relatively high (10 and $100 \mathrm{mg} / \mathrm{L})$. For ocean surface water, microplastics densities range from 0.2 to $320 \mu \mathrm{g} / \mathrm{L}$ (Nerland et al., 2014), and similar levels were found in freshwater ecosystems (Peng et al., 2017; Triebskorn et al., 2019). Data on environmental concentrations of BP3, BaP, and PFOS adsorbed to microplastics are either not available or scarce. Therefore, in the present study concentrations of pollutants adsorbed by PE were based on fish toxicity data from the literature, e.g., BP3 (Blüthgen et al., 2012; Paredes et al., 2014); BaP (Weigt et al., 2011), and PFOS (Yamashita et al., 2005).

In coastal waters, BP3 has been measured at relatively high concentrations, more than 2,000 ng/L, i.e., 2,500 times higher than the concentration used in the present study (Bratkovics and Sapozhnikova, 2011; Bratkovics et al., 2015). However, BaP and PFOS concentrations used in the present study were higher than quantified concentration in aquatic environment. Despite its high affinity to sediments, BaP can be found in the water column, however, the concentration used, i.e., $170 \mathrm{ng} / \mathrm{L}$, was five times higher than concentrations found in seawater (El Nemr and AbdAllah, 2003; Hong et al., 2016). Concentration of PFOS was also several order of magnitudes higher than concentrations detected in seawater (Ahrens et al., 2009).

\section{Acute Embryo Toxicity and Teratogenicity}

Embryotoxic and teratogenic effects were investigated for the single pollutants without MPs assuming that $100 \%$ of the 
pollutants desorb from $10 \mathrm{mg} / \mathrm{L}$ of spiked MPs. Therefore, concentrations tested for $\mathrm{BP} 3, \mathrm{BaP}$, and PFOS were assumed to be $0.0008,0.17$, and $0.7 \mu \mathrm{g} / \mathrm{L}$, respectively. For none of the compounds, any embryotoxic effects were observed, which is in agreement with the fact that the concentrations tested were several magnitudes lower than concentrations inducing toxicity reported in the literature for different aquatic organisms. For instance, immobilization tests with Daphnia magna at $48 \mathrm{~h}$ showed an $\mathrm{EC}_{50}$ for $\mathrm{BP} 3$ between 1.67 and $1.9 \mathrm{mg} / \mathrm{L}$ (Fent et al., 2010; Sieratowicz et al., 2011). Sublethal effects of BP3 in zebrafish, rainbow trout (Oncorhynchus mykiss) and Japanese medaka (Oryzias latipes) were observed from $132 \mu \mathrm{g} / \mathrm{L}$ (Coronado et al., 2008; Blüthgen et al., 2012; Kim and Choi, 2014). A previous study showed that a $72 \mathrm{~h}$ exposure to $\mathrm{BaP}$ induced teratogenic and lethal effects zebrafish embryos at 63 and $126 \mu \mathrm{g} / \mathrm{L}$, respectively (Weigt et al., 2011). PFOS produced sublethal and lethal effects in zebrafish embryos at $10 \mathrm{mg} / \mathrm{L}$ (Shi et al., 2008).

Likewise, PE particles up to $100 \mathrm{mg} / \mathrm{L}$ (with a diameter between 11 and $13 \mu \mathrm{m}$ ) without pollutants did not show any embryotoxic or teratogenic effects after $96 \mathrm{~h}$ of exposure. Similar results were found after exposure of marine medaka (Oryzias melastigma) using $10 \mathrm{mg} / \mathrm{L}$ of $11-13 \mu \mathrm{m}$ PE particles (Beiras et al., 2018). Lithner et al. (2011) ranked polymers based on monomer hazard classification, and PE was classified as one of the less hazardous polymers for humans and the environment.

Regarding MPs spiked with pollutants, in the only comparable experiment so far, embryonic stages of marine medaka were exposed to $10 \mathrm{mg} / \mathrm{L}$ PE spiked with BP3 at the same concentration as in present study. Exposure to $\mathrm{MP}+\mathrm{BP} 3$ induced premature hatching and a significant decrease in hatching rate (Beiras et al., 2018). The same authors also demonstrated a direct contact of MPs to villi at the surface of the marine medaka chorion, which may facilitate the uptake of toxicants. Although villi or similar structures do not exist on the zebrafish chorion, Batel et al. (2018) have shown that small MPs $(1-5 \mu \mathrm{m})$ were able to adhere to the outer surface of the zebrafish chorion and to transfer $\mathrm{BaP}$ to embryos across the chorion. In order to force contact of the embryos with MPs, the exposure protocol by Ifremer used a smaller water volume than the other laboratories; yet this exposure protocol failed to induce toxic effects.

Differences have been observed between zebrafish and medaka, and beside the difference in egg surface (Hart and Donovan, 1983; Hart et al., 1984), which may interfere with MPs contact, additional factors such as exposure time might also account for the different responses observed between marine medaka and zebrafish. Indeed, different sensitivities in lethal and sublethal endpoints have been demonstrated between early life stages of Japanese medaka and zebrafish exposed to sediments spiked with two models PAHs (Perrichon et al., 2014). In the frame of FET test, one major difference between these two species is the duration of embryonic stage. For Japanese medaka, the embryonic stage lasts until days 10-11 dpf (Padilla et al., 2009), whereas this period is restricted to $48-72 \mathrm{hpf}$ in zebrafish, depending on temperature (Kimmel et al., 1995). Similarly to Japanese medaka, mean hatching time for marine medaka is 11 dpf (Beiras et al., 2018). Therefore, future investigations on MPs effects in zebrafish might consider prolonged or even chronic exposure; however, this would be an animal experiment clearly requiring authorization under Directive 2010/63/EU.

\section{Cytochrome P450 Induction and Biotransformation}

CYP1A is involved in phase I of xenobiotic metabolism and is often used as a biomarker of exposure. For the investigation of sublethal effects due to MP exposures, changes in CYP1A expression was evaluated by analyzing (a) EROD activity in $96 \mathrm{~h}$ old zebrafish embryos exposed to $100 \mathrm{mg} / \mathrm{L}$ of MPs for $3 \mathrm{~h} \mathrm{(93-}$ $96 \mathrm{hpf})$ or $96 \mathrm{~h}(0-96 \mathrm{hpf})$ and (b) cypla gene transcription. Since previous studies documented short-term ( $3 \mathrm{~h}$ pulse) exposure to reference molecules to cause a more prominent EROD induction than $72 \mathrm{~h}$ continuous exposure (Kais et al., 2017, 2018) and has been shown to be long enough to induce cyp1 transcription (Larcher et al., 2014), the present study tested cyp 1 a transcription levels after short-term exposure to $10 \mathrm{mg} / \mathrm{L}$ MPs for $3 \mathrm{~h}$ only. Independent of MP concentrations, MPs alone did not induce EROD activity nor cypla transcription.

For BP3, only the short-term exposure (93-96 hpf) to 100 $\mathrm{mg} / \mathrm{L} \mathrm{MPs}+\mathrm{BP} 3$ significantly induced EROD activity $(p<$ $0.05)$, while cyp $1 a$ transcription was slightly upregulated ( $p$ $<0.1$ ) after exposure to MP + BP3 at $10 \mathrm{mg} / \mathrm{L}$. To our knowledge, BP3 induction of EROD activity has never been shown before in embryonic stages of aquatic organisms. In adult zebrafish, Blüthgen et al. (2012) documented an increase in cypla transcription in the brain of adult zebrafish after 14 days exposure to $312 \mu \mathrm{g} / \mathrm{L} \mathrm{BP3}$.

$\mathrm{BaP}$ is well-known to modulate EROD activity and to induce cyp1a transcription in various species (Jönsson et al., 2009; Rochman et al., 2013b; Batel et al., 2016). In the present study, MPs spiked with BaP caused an induction of EROD activity after $96 \mathrm{~h}$ of exposure. Meanwhile, a significant induction $(p<0.05)$ of cyp 1 a transcription was also shown after $3 \mathrm{~h}$ of continuous exposure to BaP-spiked MPs.

MPs spiked with PFOS did not modify EROD activity, but induced cyp 1 a transcription upregulation. Both in adult marine medaka and zebrafish, previous studies showed that PFOS modifies cyp $1 a$ transcription after exposure to $1-16 \mathrm{mg} / \mathrm{L}$ PFOS (Fang et al., 2012; Jantzen et al., 2016).

Albeit with some differences in response with respect to exposure duration-which may reflect the need for translation or enzyme accumulation - an overall triggering of CYP1A (either as EROD activities and/or as cypla transcription) was observed after exposure to MPs spiked with pollutants, whereas virgin MPs failed to do so. Results indicate that pollutants spiked on MPs are able to desorb and reach concentrations sufficient to induce biotransformation.

\section{Larval Behavior}

An increasing number of studies uses behavioral responses to monitor sublethal effects of pollutants such as PFOS or BPA on aquatic organisms (Huang et al., 2010; Wang J. et al., 2015), and changes in, e.g., the photomotor response are commonly interpreted as evidence of potential neurotoxicity (Le Bihanic 
et al., 2015; Legradi et al., 2018). Yet, our results did not show any alteration of the LPMR by any of the different MPs preparations. Similar results were shown after exposure of zebrafish embryos to pure polystyrene MPs particles by Chen et al. (2017), who spiked polystyrene MPs with EE2 ( $17 \alpha$-ethinylestradiol) and found hypoactivity at elevated concentrations only. However, previous studies showed that microplastics may reduce other behavioral parameters such as predatory performance of fish depending on the shape of plastic particles (de Sá et al., 2015; Choi et al., 2018).

As water-borne pollutants, both PFOS (Huang et al., 2010) and $\mathrm{BaP}$ (Knecht et al., 2017) were shown to be able to modify the behavior of zebrafish. However, concentrations applied in these studies were several magnitudes higher than those used in this study and most likely lacked any environmental relevance. Therefore, further investigations are required to assess the toxicity of microplastics on behavioral aspects considering different endpoints and different kind of particles.

\section{CONCLUSIONS}

The current study shows that both virgin MPs and MPs spiked with $\mathrm{BP} 3, \mathrm{BaP}$, or PFOS at given concentrations do not cause acute toxic effects in zebrafish embryos using the standardized protocol of OECD TG 236 (FET). Thus, the standard FET may not be sensitive enough to investigate acute embryotoxic effects of spiked MPs. Likewise, behavioral endpoints such as the LPMR were not altered under any conditions tested, even though existing literature indicate that embryonic and larval behavior of fish may be altered by MPs. Yet, given that the FET can easily be supplemented with additional (more sensitive) endpoints, enhanced FET protocols may be designed to record more subtle sublethal endpoints such as biotransformation. For the identification of adverse effects due to exposure to MPs and associated pollutants, more sensitive biomarkers or other fish models with a longer embryonic stage (i.e., Japanese or marine medaka) may thus be needed. Results indicate that sublethal toxic effects are more likely caused by pollutants associated with MPs than by the MPs themselves. This lends some support to the view that MPs might play a certain role as a vector of pollutants. Further research at more environmentally relevant MPs concentrations is needed with different types and sizes of MPs, other pollutants and adapted exposures scenarios including increased exposure duration.

\section{REFERENCES}

Ahrens, L., Felizeter, S., and Ebinghaus, R. (2009). Spatial distribution of polyfluoroalkyl compounds in seawater of the German Bight. Chemosphere 76, 179-184. doi: 10.1016/j.chemosphere.2009.03.052

Andrady, A. L. (2011). Microplastics in the marine environment. Mar. Pollut. Bull. 62, 1596-1605. doi: 10.1016/j.marpolbul.2011. 05.030

Andrady, A. L., and Neal, M. A. (2009). Applications and societal benefits of plastics. Philos. Trans. R. Soc. B. Biol. Sci. 364, 1977-1984. doi: 10.1098/rstb.2008.0304

\section{DATA AVAILABILITY}

The datasets generated for this study are available on request to the corresponding author.

\section{AUTHOR CONTRIBUTIONS}

$\mathrm{AB}, \mathrm{BC}, \mathrm{SK}, \mathrm{TB}$, and $\mathrm{XC}$ designed the experiment. $\mathrm{AB}, \mathrm{BC}$, and $\mathrm{XC}$ performed the experiments and analyzed the data. $\mathrm{AB}$ conducted $\mathrm{P} 450$ biomarker analyses. XC conducted cyp1a gene transcription and behavioral analyses. BC prepared and characterized the contaminated MPs, performed the chemical analyses. BC drafted the manuscript and AB, JC, M-LB, SK, TB, and $\mathrm{XC}$ corrected the manuscript.

\section{FUNDING}

This work was developed under the EPHEMARE project (Ecotoxicological effects of microplastics in marine ecosystems), supported by national funding agencies within the framework of JPI Oceans (FCT JPIOCEANS/0005/2015; FORMAS, 2015-01865; ANR15-JOCE-0002-01; German BMBF 03F0735A). BC was directly supported by an IdEx grant from the University of Bordeaux; AB was awarded a scholarship by the German Academic Scholarship Foundation (Studienstiftung des Deutschen Volkes).

\section{ACKNOWLEDGMENTS}

The authors would like to thank (1) Anna Karmann and Leo Yeung for their skillful collaboration to the PFOS analyses; (2) Maria Larsson for her help and supervision with the $\mathrm{BaP}$ analyses; (3) Patrick Van Hees and EUROFINS Germany for their collaboration to the BP3 analyses; (4) Ezvin Le Roux for performing some FET experiments at Örebro University; and (5) Lucette Joassard at IFREMER for technical support in running the qPCR analyses.

\section{SUPPLEMENTARY MATERIAL}

The Supplementary Material for this article can be found online at: https://www.frontiersin.org/articles/10.3389/fenvs. 2019.00135/full\#supplementary-material

Antunes, J. C., Frias, J. G. L., Micaelo, A. C., and Sobral, P. (2013). Resin pellets from beaches of the Portuguese coast and adsorbed persistent organic pollutants. Estuar. Coast. Shelf Sci. 130, 62-69. doi: 10.1016/j.ecss.2013. 06.016

Bakir, A., O'Connor, I. A., Rowland, S. J., Hendriks, A. J., and Thompson, R. C. (2016). Relative importance of microplastics as a pathway for the transfer of hydrophobic organic chemicals to marine life. Environ. Pollut. 219, 56-65. doi: 10.1016/j.envpol.2016.09.046

Bakir, A., Rowland, S. J., and Thompson, R. C. (2014). Enhanced desorption of persistent organic pollutants from microplastics under simulated physiological conditions. Environ. Pollut. 185, 16-23. doi: 10.1016/j.envpol.2013.10.007 
Barnes, D. K., Galgani, F., Thompson, R. C., and Barlaz, M. (2009). Accumulation and fragmentation of plastic debris in global environments. Philos. Trans. $R$. Soc. B. Biol. Sci. 364, 1985-1998. doi: 10.1098/rstb.2008.0205

Batel, A., Borchert, F., Reinwald, H., Erdinger, L., and Braunbeck, T. (2018). Microplastic accumulation patterns and transfer of benzo[a]pyrene to adult zebrafish (Danio rerio) gills and zebrafish embryos. Environ. Pollut. 235, 918-930. doi: 10.1016/j.envpol.2018.01.028

Batel, A., Linti, F., Scherer, M., Erdinger, L., and Braunbeck, T. (2016). Transfer of benzo[a]pyrene from microplastics to Artemia nauplii and further to zebrafish via a trophic food web experiment: CYP1A induction and visual tracking of persistent organic pollutants. Environ. Toxicol. Chem. 35, 1656-1666. doi: 10.1002/etc.3361

Beiras, R., Bellas, J., Cachot, J., Cormier, B., Cousin, X., Engwall, M., et al. (2018). Ingestion and contact with polyethylene microplastics does not cause acute toxicity on marine zooplankton. J. Hazard. Mater. 360, 452-460. doi: 10.1016/j.jhazmat.2018.07.101

Belanger, S. E., Rawlings, J. M., and Carr, G. J. (2013). Use of fish embryo toxicity tests for the prediction of acute fish toxicity to chemicals. Environ. Toxicol. Chem. 32, 1768-1783. doi: 10.1002/etc.2244

Blüthgen, N., Zucchi, S., and Fent, K. (2012). Effects of the UV filter benzophenone-3 (oxybenzone) at low concentrations in zebrafish (Danio rerio). Toxicol. Appl. Pharmacol. 263, 184-194. doi: 10.1016/j.taap.2012.06.008

Boehler, S., Lörracher, A. K., Schubert, J., and Braunbeck, T. (2018). Comparative live-imaging of in vivo EROD (ethoxyresorufin-O-deethylase) induction in zebrafish (Danio rerio) and fathead minnow (Pimephales promelas) embryos after exposure to PAHs and river sediment extracts. Sci. Total Environ. 621, 827-838. doi: 10.1016/j.scitotenv.2017.11.101

Bour, A., Haarr, A., Keiter, S., and Hylland, K. (2018). Environmentally relevant microplastic exposure affects sediment-dwelling bivalves. Environ. Pollut. 236, 652-660. doi: 10.1016/j.envpol.2018.02.006

Bratkovics, S., and Sapozhnikova, Y. (2011). Determination of seven commonly used organic UV filters in fresh and saline waters by liquid chromatography-tandem mass spectrometry. Anal. Methods. 3, 2943-2950. doi: 10.1039/clay05390f

Bratkovics, S., Wirth, E., Sapozhnikova, Y., Pennington, P., and Sanger, D. (2015). Baseline monitoring of organic sunscreen compounds along South Carolina's coastal marine environment. Mar. Pollut. Bull. 101, 370-377. doi: 10.1016/j.marpolbul.2015.10.015

Braunbeck, T., Boettcher, M., Hollert, H., Kosmehl, T., Lammer, E., Leist, E., et al. (2005). Towards an alternative for the acute fish $\mathrm{LC}_{50}$ test in chemical assessment: The zebrafish (Danio rerio) embryo toxicity test - an update. ALTEX 22, 87-102. Available online at: http://www.altex.ch/resources/altex 2005_2_87_102_Braunbeck.pdf

Braunbeck, T., Kais, B., Lammer, E., Otte, J., Schneider, K., Stengel, D., et al. (2015). The fish embryo test (FET): origin, applications, and future. Environ. Sci. Pollut. Res. Int. 22, 16247-16261. doi: 10.1007/s11356-014-3814-7

Châtel, A., Bruneau, M., Lièvre, C., Goupil, A., and Mouneyrac, C. (2017). Spermatozoa: a relevant biological target for genotoxicity assessment of contaminants in the estuarine bivalve Scrobicularia plana. Mar. Pollut. Bull. 116, 488-490. doi: 10.1016/j.marpolbul.2016.12.062

Chen, Q., Gundlach, M., Yang, S., Jiang, J., Velki, M., Yin, D., et al. (2017). Quantitative investigation of the mechanisms of microplastics and nanoplastics toward zebrafish larvae locomotor activity. Sci. Total Environ. 584-585, 1022-1031. doi: 10.1016/j.scitotenv.2017.01.156

Choi, J. S., Jung, Y.-J., Hong, N.-H., Hong, S. H., and Park, J.-W. (2018). Toxicological effects of irregularly shaped and spherical microplastics in a marine teleost, the sheepshead minnow (Cyprinodon variegatus). Mar. Pollut. Bull. 129, 231-240. doi: 10.1016/j.marpolbul.2018.02.039

Cole, M., Lindeque, P., Halsband, C., and Galloway, T. S. (2011). Microplastics as contaminants in the marine environment: a review. Mar. Pollut. Bull. 62, 2588-2597. doi: 10.1016/j.marpolbul.2011.09.025

Collins, J. F., Brown, J. P., Dawson, S. V., and Marty, M. A. (1991). Risk assessment for benzo[a]pyrene. Regul. Toxicol. Pharmacol. 13, 170-184. doi: 10.1016/0273-2300(91)90020-V

Coronado, M., De Haro, H., Deng, X., Rempel, M. A., Lavado, R., and Schlenk, D. (2008). Estrogenic activity and reproductive effects of the UV-filter oxybenzone (2-hydroxy-4-methoxyphenyl-methanone) in fish. Aquat. Toxicol. 90, 182-187. doi: 10.1016/j.aquatox.2008.08.018 de Sá, L. C., Luís, L. G., and Guilhermino, L. (2015). Effects of microplastics on juveniles of the common goby (Pomatoschistus microps): confusion with prey, reduction of the predatory performance and efficiency, and possible influence of developmental conditions. Environ. Pollut. 196, 359-362. doi: 10.1016/j.envpol.2014.10.026

Derraik, J. G. (2002). The pollution of the marine environment by plastic debris: a review. Mar. Pollut. Bull. 44, 842-852. doi: 10.1016/S0025-326X(02)00220-5

El Nemr, A., and Abd-Allah, A. M. A. (2003). Contamination of polycyclic aromatic hydrocarbons (PAHs) in microlayer and subsurface waters along Alexandria coast, Egypt. Chemosphere 52, 1711-1716. doi: 10.1016/S0045-6535(03)00300-X

Eriksson, U., Roos, A., Lind, Y., Hope, K., Ekblad, A., and Kärrman, A. (2016). Comparison of PFASs contamination in the freshwater and terrestrial environments by analysis of eggs from osprey (Pandion haliaetus), tawny owl (Strix aluco), and common kestrel (Falco tinnunculus). Environ. Res. 149, 40-47. doi: 10.1016/j.envres.2016.04.038

EU (2010). Directive 2010/63/EU of the European parliament and of the council of 22 September 2010 on the protection of animals used for scientific purposes. Off. J. EU. L276, 33-79. Available online at: https://eur-lex. europa.eu/LexUriServ/LexUriServ.do?uri=OJ:L:2010:276:0033:0079:en:PDF

Fang, C., Wu, X., Huang, Q., Liao, Y., Liu, L., Qiu, L., et al. (2012). PFOS elicits transcriptional responses of the ER, AHR and PPAR pathways in Oryzias melastigma in a stage-specific manner. Aquat. Toxicol. 106-107, 9-19. doi: 10.1016/j.aquatox.2011.10.009

Fent, K., Kunz, P. Y., Zenker, A., and Rapp, M. (2010). A tentative environmental risk assessment of the UV-filters 3-(4-methylbenzylidenecamphor), 2-ethyl-hexyl-4-trimethoxycinnamate, benzophenone-3, benzophenone-4 and 3-benzylidene camphor. Mar. Environ. Res. 69, S4-S6. doi: 10.1016/j.marenvres.2009.10.010

Giesy, J. P., and Kannan, K. (2002). Perfluorochemical surfactants in the environment. Environ. Sci. Technol. 36, 146A-152A. doi: 10.1021/es022253t

Hart, N. H., and Donovan, M. (1983). Fine structure of the chorion and site of sperm entry in the egg of Brachydanio. J. Exp. Zool. 227, 277-296. doi: $10.1002 /$ jez.1402270212

Hart, N. H., Pietri, R., and Donovan, M. (1984). The structure of the chorion and associated surface filaments in Oryzias-evidence for the presence of extracellular tubules. J. Exp. Zool. 230, 273-296. doi: 10.1002/jez.1402300213

Hong, W.-J., Jia, H., Li, Y.-F., Sun, Y., Liu, X., and Wang, L. (2016). Polycyclic aromatic hydrocarbons (PAHs) and alkylated PAHs in the coastal seawater, surface sediment and oyster from Dalian, Northeast China. Ecotoxicol. Environ. Saf. 128, 11-20. doi: 10.1016/j.ecoenv.2016.02.003

Huang, H., Huang, C., Wang, L., Ye, X., Bai, C., Simonich, M. T., et al. (2010). Toxicity, uptake kinetics and behavior assessment in zebrafish embryos following exposure to perfluorooctanesulphonicacid (PFOS). Aquat. Toxicol. 98, 139-147. doi: 10.1016/j.aquatox.2010.02.003

Jambeck, J. R., Geyer, R., Wilcox, C., Siegler, T. R., Perryman, M., Andrady, A., et al. (2015). Plastic waste inputs from land into the ocean. Science 347, 768-771. doi: 10.1126/science. 1260352

Jantzen, C. E., Annunziato, K. A., Bugel, S. M., and Cooper, K. R. (2016). PFOS, PFNA, and PFOA sub-lethal exposure to embryonic zebrafish have different toxicity profiles in terms of morphometrics, behavior and gene expression. Aquat. Toxicol. 175, 160-170. doi: 10.1016/j.aquatox.2016. 03.026

Jönsson, M. E., Brunström, B., and Brandt, I. (2009). The zebrafish gill model: induction of CYP1A, EROD and PAH adduct formation. Aquat. Toxicol. 91, 62-70. doi: 10.1016/j.aquatox.2008.10.010

Kais, B., Ottermanns, R., Scheller, F., and Braunbeck, T. (2018). Modification and quantification of in vivo EROD live-imaging with zebrafish (Danio rerio) embryos to detect both induction and inhibition of CYP1A. Sci. Total Environ. 615, 330-347. doi: 10.1016/j.scitotenv.2017.09.257

Kais, B., Schiwy, S., Hollert, H., Keiter, S. H., and Braunbeck, T. (2017). In vivo EROD assays with the zebrafish (Danio rerio) as rapid screening tools for the detection of dioxin-like activity. Sci. Total Environ. 590-591, 269-280. doi: 10.1016/j.scitotenv.2017.02.236

Karami, A., Groman, D. B., Wilson, S. P., Ismail, P., and Neela, V. K. (2017). Biomarker responses in zebrafish (Danio rerio) larvae exposed to pristine low-density polyethylene fragments. Environ. Pollut. 223, 466-475. doi: 10.1016/j.envpol.2017.01.047 
Keiter, S., Burkhard-Medicke, K., Kais, B., Färber, H., Skutlarek, D., Engwall, M., et al. (2016). Does perfluorooctane sulfonate (PFOS) act as chemosensitizer in zebrafish embryos? Sci. Total Environ. 548-549, 317-324. doi: $10.1016 /$ j.scitotenv.2015.12.089

Kim, S., and Choi, K. (2014). Occurrences, toxicities, and ecological risks of benzophenone-3, a common component of organic sunscreen products: a mini-review. Environ. Int. 70, 143-157. doi: 10.1016/j.envint.2014. 05.015

Kimmel, C. B., Ballard, W. W., Kimmel, S. R., Ullmann, B., and Schilling, T. F. (1995). Stages of embryonic development of the zebrafish. Dev. Dyn. 203, 253-310. doi: 10.1002/aja.1002030302

Kinnberg, K. L., Petersen, G. I., Albrektsen, M., Minghlani, M., Awad, S. M., Holbech, B. F., et al. (2015). Endocrine-disrupting effect of the ultraviolet filter benzophenone-3 in zebrafish, Danio rerio. Environ. Toxicol. Chem. 34, 2833-2840. doi: 10.1002/etc.3129

Knecht, A. L., Truong, L., Simonich, M. T., and Tanguay, R. L. (2017). Developmental benzo[a]pyrene $(\mathrm{B}[\mathrm{a}] \mathrm{P})$ exposure impacts larval behavior and impairs adult learning in zebrafish. Neurotoxicol. Teratol. 59, 27-34. doi: 10.1016/j.ntt.2016.10.006

Koelmans, A. A., Bakir, A., Burton, G. A., and Janssen, C. R. (2016). Microplastic as a vector for chemicals in the aquatic environment: critical review and model-supported reinterpretation of empirical studies. Environ. Sci. Technol. 50, 3315-3326. doi: 10.1021/acs.est.5b06069

Koelmans, A. A., Besseling, E., Wegner, A., and Foekema, E. M. (2013). Plastic as a carrier of POPs to aquatic organisms: a model analysis. Environ. Sci. Technol. 47, 7812-7820. doi: 10.1021/es401169n

Lammer, E., Carr, G. J., Wendler, K., Rawlings, J. M., Belanger, S. E., and Braunbeck, T. (2009). Is the fish embryo toxicity test (FET) with the zebrafish (Danio rerio) a potential alternative for the fish acute toxicity test? Comp. Biochem. Physiol. C. 149, 196-209. doi: 10.1016/j.cbpc.2008.11.006

Larcher, T., Perrichon, P., Vignet, C., Ledevin, M., Le Menach, K., Lyphout, L., et al. (2014). Chronic dietary exposure of zebrafish to PAH mixtures results in carcinogenic but not genotoxic effects. Environ. Sci. Pollut. Res. 21:13833. doi: $10.1007 /$ s11356-014-2923-7

Larsson, M., Hagberg, J., Rotander, A., van Bavel, B., and Engwall, M. (2013). Chemical and bioanalytical characterisation of PAHs in risk assessment of remediated PAH-contaminated soils. Environ. Sci. Pollut. Res. 20, 8511-8520. doi: 10.1007/s11356-013-1787-6

Le Bihanic, F., Sommard, V., Perrine de, L., Pichon, A., Grasset, J., Berrada, S., et al. (2015). Environmental concentrations of benz[a]anthracene induce developmental defects and DNA damage and impair photomotor response in Japanese medaka larvae. Ecotoxicol. Environ. Saf. 113, 321-328. doi: 10.1016/j.ecoenv.2014.12.011

Lee, H., Shim, W. J., and Kwon, J.-H. (2014). Sorption capacity of plastic debris for hydrophobic organic chemicals. Sci. Total Environ. 470-471, 1545-1552. doi: 10.1016/j.scitotenv.2013.08.023

Legradi, J. B., Di Paolo, C., Kraak, M. H. S., van der Geest, H. G., Schymanski, E. L., Williams, A. J., et al. (2018). An ecotoxicological view on neurotoxicity assessment. Environ. Sci. Eur. 30:46. doi: 10.1186/s12302-0180173-x

Lithner, D., Larsson, Å., and Dave, G. (2011). Environmental and health hazard ranking and assessment of plastic polymers based on chemical composition. Sci. Total Environ. 409, 3309-3324. doi: 10.1016/j.scitotenv.2011.04.038

Liu, T., Pan, L., Jin, Q., and Cai, Y. (2015). Differential gene expression analysis of benzo(a)pyrene toxicity in the clam, Ruditapes philippinarum. Ecotoxicol. Environ. Saf. 115, 126-136. doi: 10.1016/j.ecoenv.2015. 02.007

Lohmann, R. (2017). Microplastics are not important for the cycling and bioaccumulation of organic pollutants in the oceans-but should microplastics be considered POPs themselves? Integ. Environ. Assess. Manag. 13, 460-465. doi: 10.1002/ieam.1914

Mato, Y., Isobe, T., Takada, H., Kanehiro, H., Ohtake, C., and Kaminuma, T. (2001). Plastic resin pellets as a transport medium for toxic chemicals in the marine environment. Environ. Sci. Technol. 35, 318-324. doi: 10.1021/es0010498

Nagel, R. (2002). DarT: The embryo test with the zebrafish Danio rerio - a general model in ecotoxicology and toxicology. ALTEX 19, 38-48. Available online at: http://www.altex.ch/resources/altex_2002_Supp_1_38_48_Nagel.pdf
Nerland, I. L., Halsband, C., Allan, I., and Thomas, K. V. (2014). Microplastics in Marine Environments: Occurrence, Distribution and Effects. Oslo: NIVA. Available online at: https://www.miljodirektoratet.no/globalassets/ publikasjoner/M319/M319.pdf

O’Donovan, S., Mestre, N. C., Abel, S., Fonseca, T. G., Carteny, C. C., Cormier B., et al. (2018). Ecotoxicological effects of chemical contaminants adsorbed to microplastics in the clam Scrobicularia plana. Front. Mar. Sci. 5:143. doi: $10.3389 /$ fmars.2018.00143

OECD (1992). "OECD guidelines for the testing of chemicals," in Section 2: Effects on Biotic Systems OECD Test Guideline 203: Fish, Acute toxicity Test (Paris: OECD publishing). Available online at: https://www.oecd-ilibrary. org/environment/test-no-203-fish-acute-toxicity-test_9789264069961-en

OECD (2013). "OECD Guidelines for the Testing of Chemicals," in Section 2: Effects on Biotic Systems Test No 236: Fish Embryo Acute Toxicity Test (Paris: OECD publishing). Available online at: https://www.oecdilibrary.org/environment/test-no-236-fish-embryo-acute-toxicity-fet-test_ 9789264203709-en

Padilla, S., Cowden, J., Hinton, D. E., Yuen, B., Law, S., Kullman, S. W., et al. (2009). Use of medaka in toxicity testing. Curr. Protoc. Toxicol. 39, 1.10.11-11.10.36. doi: 10.1002/0471140856.tx0110s39

Paredes, E., Perez, S., Rodil, R., Quintana, J. B., and Beiras, R. (2014). Ecotoxicological evaluation of four UV filters using marine organisms from different trophic levels Isochrysis galbana, Mytilus galloprovincialis, Paracentrotus lividus, and Siriella armata. Chemosphere 104, 44-50. doi: 10.1016/j.chemosphere.2013.10.053

Paul, A. G., Jones, K. C., and Sweetman, A. J. (2009). A first global production, emission, and environmental inventory for perfluorooctane sulfonate. Environ. Sci. Technol. 43, 386-392. doi: 10.1021/es802216n

Peng, J., Wang, J., and Cai, L. (2017). Current understanding of microplastics in the environment: Occurrence, fate, risks, and what we should do. Integr. Environ. Asses. 13, 476-482. doi: 10.1002/ieam.1912

Perrichon, P., Le Bihanic, F., Bustamante, P., Le Menach, K., Budzinski, H., Cachot, J., et al. (2014). Influence of sediment composition on $\mathrm{PAH}$ toxicity using zebrafish (Danio rerio) and Japanese medaka (Oryzias latipes) embryo-larval assays. Environ. Sci. Pollut. Res. 21, 13703-13719. doi: $10.1007 / \mathrm{s} 11356-014-3502-7$

Pfaffl, M. W. (2001). A new mathematical model for relative quantification in real-time RT-PCR. Nucleic Acids Res. 29, 2002-2007. doi: 10.1093/nar/ 29.9.e45

Pfaffl, M. W., Horgan, G. W., and Dempfle, L. (2002). Relative expression software tool (REST (c)) for group-wise comparison and statistical analysis of relative expression results in real-time PCR. Nucleic Acids Res. 30:10. doi: 10.1093/nar/30.9.e36

Pfaffl, M. W., Tichopad, A., Prgomet, C., and Neuvians, T. P. (2004). Determination of stable housekeeping genes, differentially regulated target genes and sample integrity: BestKeeper - excelbased tool using pair-wise correlations. Biotechnol. Lett. 26, 509-515. doi: 10.1023/B:BILE.0000019559.84305.47

Pittura, L., Avio, C. G., Giuliani, M. E., d'Errico, G., Keiter, S. H., Cormier, B., et al. (2018). Microplastics as vehicles of environmental PAHs to marine organisms: combined chemical and physical hazards to the mediterranean mussels, Mytilus galloprovincialis. Front. Mar. Sci. 5:103. doi: 10.3389/fmars.2018. 00103

Rios, L. M., Moore, C., and Jones, P. R. (2007). Persistent organic pollutants carried by synthetic polymers in the ocean environment. Mar. Pollut. Bull. 54, 1230-1237. doi: 10.1016/j.marpolbul.2007.03.022

Rochman, C. M., Hoh, E., Hentschel, B. T., and Kaye, S. (2013a). Long-term field measurement of sorption of organic contaminants to five types of plastic pellets: implications for plastic marine debris. Environ. Sci. Technol. 47, 1646-1654. doi: $10.1021 /$ es303700s

Rochman, C. M., Hoh, E., Kurobe, T., and Teh, S. J. (2013b). Ingested plastic transfers hazardous chemicals to fish and induces hepatic stress. Sci. Rep. 3:3263. doi: $10.1038 /$ srep03263

Rodríguez-Fuentes, G., Sandoval-Gío, J. J., Arroyo-Silva, A., Noreña-Barroso, E., Escalante-Herrera, K. S., and Olvera-Espinosa, F. (2015). Evaluation of the estrogenic and oxidative stress effects of the UV filter 3-benzophenone in zebrafish (Danio rerio) eleuthero-embryos. Ecotoxicol. Environ. Saf. 115, 14-18. doi: 10.1016/j.ecoenv.2015.01.033 
Schneider, C. A., Rasband, W. S., and Eliceiri, K. W. (2012). NIH Image to ImageJ: 25 years of image analysis. Nat. Methods 9:671. doi: 10.1038/nmeth.2089

Schönlau, C., Larsson, M., Lam, M. M., Engwall, M., Giesy, J. P., Rochman, C., et al. (2019). Aryl hydrocarbon receptor-mediated potencies in field-deployed plastics vary by type of polymer. Environ. Sci. Pollut. Res. 26, 9079-9088. doi: 10.1007/s11356-019-04281-4

Shi, X., Du, Y., Lam, P. K., Wu, R. S., and Zhou, B. (2008). Developmental toxicity and alteration of gene expression in zebrafish embryos exposed to PFOS. Toxicol. Appl. Pharmacol. 230, 23-32. doi: 10.1016/j.taap.2008.01.043

Sieratowicz, A., Kaiser, D., Behr, M., Oetken, M., and Oehlmann, J. (2011). Acute and chronic toxicity of four frequently used UV filter substances for Desmodesmus subspicatus and Daphnia magna. J. Environ. Sci. Health A. Tox. Hazard Subst. Environ. Eng. 46, 1311-1319. doi: 10.1080/10934529.2011.602936

Strähle, U., Scholz, S., Geisler, R., Greiner, P., Hollert, H., Rastegar, S., et al. (2012). Zebrafish embryos as an alternative to animal experiments-a commentary on the definition of the onset of protected life stages in animal welfare regulations. Reprod. Toxicol. 33, 128-132. doi: 10.1016/j.reprotox.2011.06.121

Teuten, E. L., Rowland, S. J., Galloway, T. S., and Thompson, R. C. (2007). Potential for plastics to transport hydrophobic contaminants. Environ. Sci. Technol. 41, 7759-7764. doi: 10.1021/es071737s

Thompson, R. C., Moore, C. J., vom Saal, F. S., and Swan, S. H. (2009). Plastics, the environment and human health: current consensus and future trends. Philos. Trans. R. Soc. B. Biol. Sci. 364, 2153-2166. doi: 10.1098/rstb.2009.0053

Thompson, R. C., Olsen, Y., Mitchell, R. P., Davis, A., Rowland, S. J., John, A. W. G., et al. (2004). Lost at sea: where is all the plastic? Science 304, 838-838. doi: $10.1126 /$ science. 1094559

Triebskorn, R., Braunbeck, T., Grummt, T., Hanslik, L., Huppertsberg, S., Jekel, M., et al. (2019). Relevance of nano- and microplastics for freshwater ecosystems: a critical review. TrAC. 110, 375-392. doi: 10.1016/j.trac.2018.11.023

Vignet, C., Le Menach, K., Lyphout, L., Guionnet, T., Frère, L., Leguay, D., et al. (2014). Chronic dietary exposure to pyrolytic and petrogenic mixtures of PAHs causes physiological disruption in zebrafish-part II: behavior. Environ. Sci. Pollut. R. 21, 13818-13832. doi: 10.1007/s11356-014-2762-6
Wang, F., Shih, K. M., and Li, X. Y. (2015). The partition behavior of perfluorooctanesulfonate (PFOS) and perfluorooctanesulfonamide (FOSA) on microplastics. Chemosphere 119, 841-847. doi: 10.1016/j.chemosphere.2014.08.047

Wang, J., Wang, X., Xiong, C., Liu, J., Hu, B., and Zheng, L. (2015). Chronic bisphenol A exposure alters behaviors of zebrafish (Danio rerio). Environ. Pollut. 206, 275-281. doi: 10.1016/j.envpol.2015.07.015

Weigt, S., Huebler, N., Strecker, R., Braunbeck, T., and Broschard, T. H. (2011). Zebrafish (Danio rerio) embryos as a model for testing proteratogens. Toxicology 281, 25-36. doi: 10.1016/j.tox.2011. 01.004

Westerfield, C. (2007). The Zebrafish Book: A Guid for the Labortary Use of Zebrafish (Danio rerio). Eugene, OR: University of Oregon Press.

Yamashita, N., Kannan, K., Taniyasu, S., Horii, Y., Petrick, G., and Gamo, T. (2005). A global survey of perfluorinated acids in oceans. Mar. Pollut. Bull. 51, 658-668. doi: 10.1016/j.marpolbul.2005. 04.026

Ziccardi, L. M., Edgington, A., Hentz, K., Kulacki, K. J., and Driscoll, S. K. (2016). Microplastics as vectors for bioaccumulation of hydrophobic organic chemicals in the marine environment: a state-of-thescience review. Environ. Toxicol. Chem. 35, 1667-1676. doi: 10.1002/ etc. 3461

Conflict of Interest Statement: The authors declare that the research was conducted in the absence of any commercial or financial relationships that could be construed as a potential conflict of interest.

Copyright (c) 2019 Cormier, Batel, Cachot, Bégout, Braunbeck, Cousin and Keiter. This is an open-access article distributed under the terms of the Creative Commons Attribution License (CC BY). The use, distribution or reproduction in other forums is permitted, provided the original author(s) and the copyright owner(s) are credited and that the original publication in this journal is cited, in accordance with accepted academic practice. No use, distribution or reproduction is permitted which does not comply with these terms. 